\title{
A FORMAÇÃO DE SI (BILDUNG) EM UM CONTEXTO EDUCATIVO RECONFIGURADO PELA CIBERCULTURA
}

\author{
Verônica Alves Conceição \\ Jonathas Fontes Santos \\ Cristiane Magalhães Porto $^{(*)}$
}

\section{INTRODUÇÃO}

Diferente de outros animais cujo desenvolvimento parece estar previamente programado por fatores biológicos, o homem traz a incompletude e a capacidade de formar-se ao nascer. A situação de vir a ser que marca o nascimento de um ser homem é o cerne de sua natureza como membro de uma espécie biologicamente programada para viver em sociedade. É no exercício da vida junto aos pares que o homem se constitui humano.

A formação de um ser recém nascido acontece no interior de um meio social que, historicamente, traz o modelo de homem e as regras que regulam as relações entre os seus membros. Com vista a formar daquele pequeno ser, os homens criaram práticas e dispositivos para ensinar o perfil ideal para o seu grupo de pertença. Esse conjunto de práticas e dispositivos constituem o que se entende por educação.

Ainda que tenham sido criadas instituições educativas responsáveis para disponibilizar os conhecimentos historicamente acumulados para os seus membros, como as escolas e as universidades, a educação, enquanto formação humana, extrapola os ambientes institucionais e acontece em todas as redes e estruturas socias. O desenvolvimento do ser, enquanto humano, é resultado de um processo educativo a que foi submetido ao longo da vida.

\footnotetext{
(*) Verônica A. Conceição. Doutoranda em Educação pela Universidade Tiradentes (UNIT), mestra em Estudos Interdisciplinares (UFBA), graduada em Pedagoga (UEFS), graduanda em Letras e Literatura Brasileira pela Universidade do Paraná (UNOPAR). Especialista em Psicopedagogia (UNEB) e Coordenação Pedagógica (UFBA). Orcid: <http://orcid.org/0000-0002-5481-0522>.

Jonathas F. Santos. Mestrando em Educação pela UNIT/SE (2018), especialista em Mídias em Educação pela UFPE (2013) e graduado em Tecnologia em Informática e Gestão da Informação pela Universidade Tiradentes (2009). Orcid: <https://orcid.org/0000-0002-5786-9896>.

Cristiane M. Porto. Doutora Multidisciplinar em Cultura e Sociedade (UFBA). Mestrado em Letras e Linguística (UFBA). Pesquisadora do Instituto de Tecnologia e Pesquisa (ITP). Bolsista em Produtividade em Pesquisa do CNPq Nível 2 e faz parte do Comitê de Assessoramento de Divulgação Científica do CNPq. Pós-doutorado em Educação (UERJ). Orcid: <https://orcid.org/0000-0001-5622-030X>.
} 
Assim, entende-se educação como um processo de formação mediante o qual o indivíduo natural se torna uma pessoa, um ser cultural. Logo, no que interessa a esse estudo, o processo de desenvolvimento e de educação se dá em uma dimensão mais ampla, a dimensão da formação de si (bildung) que extrapola as instituições de ensino ao tempo em que traz implicações para as práticas docentes que acontecem em ambiência de sala de aula.

Por outro lado, tematizar a formação de si em um contexto de Cibercultura ilumina a certeza de que a sociedade contemporânea está em processo contínuo de reconfiguração. A globalização de hábitos e modos de vida, a necessidade de divulgação da ciência para a sociedade comum, a descentralização do conhecimento e da informação e a centralização das relações de interação humana possibilitada pela tecnologia móvel caracterizam o ambiente de vida e formação do homem pós-moderno.

Pensar na interface formação de si e Cibercultura é considerar a influência do ambiente social, agora na dimensão do virtual, na performance dos estudantes que chegam às instituições de ensino, básica e superior. É reconhecer que o processo de formação dos sujeitos contemporâneos inicia-se muito antes da educação formal, como maior intensidade e em dimensões muito mais largas que a pouco tempo atrás. É convocar a educação formal a se expandir e oxigenar suas práticas com atos de vida e interação social que fervilham o ambiente extra sala de aula.

O estudo está organizado em duas seções. A primeira trata do conceito de bildung, no aspecto semântico do termo, a partir do vocábulo utilizado na Alemanha. Em seguida, aborda a formação de si (bildung) como eixo de conexão entre as discussões sobre experiência, cultura e educação.

Na segunda seção, como o enfoque voltado à Cibercultura, ilumina o deslocamento do lugar do estudante e do professor na pedagogia contemporânea e, com isso, estabelece um entendimento de que entre a Cibercultura, a experiência e a educação formal, o engajamento político de estudantes mediado pela hipermídia se mostra indispensável à materialização de uma educação ativista na Cibercultura.

Para ao fim, ressalta que o processo de formação de si (bildung) apresenta-se com força impetuosa na contemporaneidade e potencializa a Cibercultura como reconfigurante do contexto educativo onde as experiências prévias de estudantes, a cultura contemporânea e as relações sociais horizontalizadas encontram espaço de existência, significância e ativismo. 


\section{FORMAÇÃO DE SI (BILDUNG): EIXO ARTICULADOR ENTRE A EXPERIÊNCIA, A CULTURA E A EDUCAÇÃO FORMAL.}

O termo Bildung encontra sua origem na língua alemã e não possui equivalência em outros idiomas. Apesar de existir uma relação de proximidade com os termos formation, em francês e em inglês, e formação, em português, bildung abarca um sentido mais complexo e abrangente do que esses. Ele pode ser aplicado tanto no campo da educação, da pedagogia, da literatura e da filosofia quanto no campo da cultura. Por extensão, bildung, por vezes, pode vir atrelado às reflexões acerca da constituição do homem e de sua relação com a sociedade (LEITE, 2016; TOMMASELLI, 2017).

Ademais, definir bildung como educação formal incorre numa restrição de sua potencialidade, uma vez que o termo alemão mais adequado para se referir ao processo educativo, que envolve práticas de ensino e aprendizagem, seria erziehung. Apesar de, conforme Tommaselli (2017), no início do Iluminismo na Alemanha a palavra bildung ser utilizada em conjunto com erziehung para se referir a vontade de educar, com o tempo a primeira se emancipou da segunda e passou a representar o desenvolvimento humano guiado pelos critérios de independência, liberdade e autonomia.

Assim, o campo semântico da palavra bildung envolve o processo de formação de si, de construção do interior de uma pessoa nos aspectos mental, psíquico e espiritual. No dizer de Britto (2012, p. 222), bildung é "um processo de autodesenvolvimento, de autoformação dos indivíduos no que diz respeito a sua educação”. Ou, ainda, como dito por Araújo e Ribeiro (2009, p. 4), o termo está ligado a "formação-de-si-mesmo (numa linha de maturação/amadurecimento), de educação-de-si-mesmo, de desenvolvimento e aperfeiçoamento de si-mesmo".

Para Leite (2016), o processo de formação de si (bildung) escapa os limites de uma instituição formadora na medida em que o estudante exerce um certo nível de independência de pensamento que lhe permite refletir por si e sobre si em um processo potencializador de (auto)formação. Conforme a autora (2016, p. 12), esse tipo de formação "leva a uma transformação (umbildung) em direção a uma singularidade que torna o individuo um ser único, mas que se dá no contato com o outro e com o mundo".

Nesse sentido, Leite (2016, p. 12) lembra o lugar da experiência no processo de formação, pois a pessoa "se (trans)forma, afastando-se de si mesmo, indo ao encontro do mundo e, posteriormente, retornando para si. Trata-se, pois, do desenvolvimento da pessoa em direção a si através das experiências que vive". Logo, a formação de si encontra um sentido pela via da experiência. $\mathrm{O}$ indivíduo potencializa sua formação e assume a experiência formadora como 
princípio diretivo no curso da vida quando se permite um envolvimento ativo e consciente com as práticas do cotidiano, com ações que movimentam, significam e ressignificam o ato de viver.

Desta forma, a bildung está articulada com a experiência de vida, com as interações que o homem estabelece no percurso das vivências experienciadas na individualidade e na coletividade. Afinal, quando um fato ocorrido se constitui experiência e quando não o é? O que é experiência? Para Larrosa (2011, p. 5) a experiência é o "isso que me passa". Portanto, ela é constituída de três termos basilares: isso, me e passa. O primeiro, isso, trata de um acontecimento, um passar de algo que não está no aprendiz e nem depende de sua vontade. É o isso exterior ao homem e que independe do seu desejo e controle. Com o que ele estabelece uma relação de alteridade e de alienação por não ser uma propriedade particular e nem ser possível capturá-lo.

O segundo termo, me. Embora a experiência seja exterior ao homem ela está intimamente ligada as suas representações, seus sentimentos, seus projetos e intenções, por isso é na constituição pessoal que a experiência é significada, que encontra um lugar de existir. Nesse aspecto, a experiência é regida pelos princípios da reflexibilidade, pois supõe um movimento de saída de si ao encontro do outro e de retorno a si em um processo de reconstrução e formação a partir do experienciado. Cada sujeito da experiência traz uma subjetividade que lhe permite entender e vivenciar o ocorrido de uma forma singular, bem como o seu processo de transformação está condicionado a abertura, a sensibilidade e a disposição de cada pessoa se formar e (trans)formar.

Terceiro, quando Larrosa (2011) diz que a experiência é isso que me passa, o termo passar indica que ela é um passo, um percurso. Mas, durante sua passagem, ela deixa marcas, rastros que ficam na composição do novo homem, reformulado pelo ocorrido, embora, por vezes, não tenha sido causado por ele. É nesse sentido que, Larrosa (2011, p. 16) lembra que a experiência é constituída do imprevisível, do indizível e do imprescritível. Afinal, "a abertura que a experiência dá é a abertura do possível, mas também do impossível, do surpreendente, do que não pode ser.”.

De fato, a experiência é um aspecto importante da formação de si (bildung), posto que o processo de formação do homem é tão longo quanto a duração da própria vida. Ainda, ela não tem um fim em si mesmo, na medida em que ao se humanizar, o indivíduo, consequentemente humaniza o coletivo, a sociedade. A formação de si implica sair de si mesmo, ir ao encontro do mundo e, posteriormente, retornar a si em estado renovado, mais amadurecido, mais humano.

Assim, a formação de si (bildung) como resultado de experiências passadas podem ser impulsionadora de práticas de vivência e convivência mais tolerantes em meio as diversidades que marcam a contemporaneidade, a Cibercultura. É na interação como o outro, também possuidor de 
experiências e em processo de formação, que o humano se forma ao passo que forma o outro. É no seio da interação social que o homem desenha a compreensão de si e estabelece características de semelhanças e diferenças em relação a coletividade. Nesse processo identifica a si como ator e como membro de um grupo, seu grupo de pertença.

A experiência a partir de uma coletividade é normalizada pela kultur (cultura, em alemão). A cultura é outro aspecto importante da bildung e com a qual mantém, ainda hoje, uma relação de proximidade. O que não é de se estranhar, pois ao tempo que a formação de si é construída, principalmente, pela via da experiência, ela acontece em um ambiente social, na interação entre seus componentes.

É no contexto de interações socias estabelecidas no interior de um grupo social que o indivíduo se confronta com as normas, as crenças e os valores que o formam. Na mesma dinâmica, ele transforma o outro com quem interage, consequentemente, remodela o seu ambiente, sua realidade. Esse espaço-tempo de vida chama-se cultura (kultur). Segundo Johnson (1997, p. 59), cultura é "o conjunto acumulado de símbolos, ideias e produtos materiais associados a um sistema social, seja ele uma sociedade inteira ou uma família." Associada à estrutura social, a população e a ecologia, o autor entende que ela "constitui um dos principais elementos de todos os sistemas sociais e é conceito fundamental na definição da perspectiva sociológica."

A relação de implicação da cultura (kultur) com a formação do indivíduo (bildung) foi abordada por Immanuel Kant (1724 a 1804) e por Antônio Gramsci (1891 a 1937), dentre outros filósofos, nos século XVIII e XIX. Tommaselli (2017) diz que Kant apontou a articulação entre os conceitos de formação (bildung) e de cultura (kultur) a partir do processo de esclarecimento (aufklärung) do povo alemão. Para Tommaselli (2017, p. 95), Kant entendia como imprescindível o estabelecimento de relações entre os dois conceitos e o conceito de educação. Assim, a bildung surgiu "como fruto do desenvolvimento do problema cultural próprio do esclarecimento"

Conforme Vieira (1999, p. 61), nos escritos de Gramsci, o conceito de cultura assume duas direções. Em primeiro lugar, cultura "significa o modo de viver, de pensar e de sentir a realidade por parte de uma civilização" e, em segundo, ela é entendida "como projeto de formação do indivíduo, como ideal educativo a ser transmitido para as novas gerações."

Para Vieira (1999), a cultura se compõe de múltiplas ambiências, como a família, a região, a língua, a classe social etc. E é a sua diversidade que produz um horizonte de formação (bildung) no homem. Ainda, a cultura não é estática, pois é o resultado do confronto e da interação de 
concepções de mundo, das experiências e dos atos de consciência social. Como o homem muda com o tempo, suas concepções também sofrem mudanças e, como isso, sua realidade se transforma.

A contemporaneidade e o advento das tecnologias digitais, por exemplo, trouxeram transformações de natureza estética e semiótica nas práticas cotidianas e nos modos de agir e interagir do indivíduo. As novas maneiras de enxergar a realidade e viver em sociedade perfila um novo ambiente onde se reconfigurem e ressignifiquem a cultura em um novo contexto de comunicação e de educação, e por extensão o processo de formação de si.

Outro fator a ser considerado é que as mudanças nas conjunturas socioculturais interferem nos comportamentos e nos modos de interagir do homem contemporâneo. Xavier (2005) aponta princípios de ação que norteiam a comunicação entre os atores socias, especialmente em contexto imersivo em redes digitais: o imediatismo interacional, a tolerância ao diferente e a autonomia na aprendizagem.

O imediatismo interacional é acionado pela necessidade de demonstrar agilidade em participar de situações de interação, especialmente em rede online. Um internauta vagaroso percebe a possibilidade de perder um momento de participação e de ter a sua contribuição desconsiderada. A tolerância ao diferente é evidenciada em medida que a transgressão às regras gramaticais e culturais, e o rompimento com todo tipo de padronização são vistos como manifestações de criatividade e de descontração, tanto no uso da linguagem, quanto da roupa e do estilo de vida. E, a autonomia na aprendizagem permite testar novas formas de verbalizar o discurso, regulamentar a escrita em novas situações de comunicação e a opção por modelos de aprendizagens diferentes e, muitas vezes, online.

Finalmente, a bildung encontra o terceiro ponto de seu eixo: a educação formal. Assim, qual o lugar da educação institucionalizada na vida de um indivíduo que forma a si pela via da experiência e da cultura? Que relação aproxima a formação de si (bildung) da educação (erziehung)?

O lugar e a função da educação formal tem sido tema de controvérsias entre educadores, políticos e leigos. Para Goergen (2013), a educação na contemporaneidade apresenta dois movimentos opostos. De um lado, a educação é compreendida como relevante e central, a força motriz que possibilitará resolver os problemas do homem. Do outro, a educação encontra um sentido quando ensina conhecimentos predominantemente úteis. Dito de modo simples, no primeiro, ela é salvadora e no segundo é funcional. 
Há ainda, aqueles que entendem a educação como um bem público, portanto com a responsabilidade de formar profissionais mais, também, cidadãos. Nesse grupo estão educadores que, ao assumirem uma postura crítica-reflexiva, defendem uma educação formal capaz de contribuir para a formação (bildung) de profissionais-cidadãos disposto a participar na construção de uma sociedade mais humana, tolerante e democrática.

Aqui, a educação é compreendida como um processo de formação do ser humano com vistas à sua humanização. E, ainda que a formação de si (bildung) possa se dar em todas as redes e estruturas sociais, a educação formal contribui no processo de humanização na medida em que disponibiliza os conhecimentos produzidos ao longo da história da humanidade.

Conforme Severino (2006, p.622), o ser nascido de um homem "tem necessidade de cuidar de si mesmo como que buscando um estágio de maior humanidade, uma condição de maior perfeição em seu modo de ser humano." É a partir do entendimento do autor que a educação institucionalizada se une a experiência e da cultura para fortalecer a formação de si (bildung) que torna o homem em humano. Portanto, no dizer de Severino (2006, p.622), “a formação é processo do devir humano como devir humanizador, mediante o qual o indivíduo natural devém um ser cultural, uma pessoa".

Por fim, a formação do homem envolve um empreendimento particular e autônomo que o torna mais tolerante, acolhedor das diferenças e cuidadoso de si e do outro, ela acontece pelas vias das experiências formadoras e das interações sociais estabelecidas em ambientes culturais, físicos e virtuais, e fortalecidos pela educação escolar. No entanto, as mudanças pelas quais o homem tem passado nas últimas décadas cobraram ajustes na cultura, no modo como se passa a experiência e nos modelos pedagógicos institucionalizados. A última parece ser mais resistente para aceitar as emergentes formas de se aprender e formar-se, portanto cabe um destaque específico nesse estudo.

\section{A CIBERCULTURA: O DESLOCAMENTO DO ESTUDANTE E DO PROFESSOR.}

Nos anos de 1990 a revolução digital permitiu que diferentes tipos de informações fossem convertidas por computadores numa linguagem universal, a digital. Digitalização e compressão de dados, tradução de diferentes mídias, manipulação, armazenamento, reprodução e distribuição de informações revelaram o início do fenômeno da convergência das mídias (SANTAELLA, 2003).

Após esse cenário de convergência, explodiu a distribuição e a difusão de informações em razão da ligação da informática com as telecomunicações. Como resultado se formaram as "redes 
de transmissão, acesso e troca de informações que hoje conectam todo o globo na constituição de novas formas de socialização e de cultura" (SANTAELLA, 2003, p. 60), ou seja, a Cibercultura.

O fenômeno em seu ritmo acelerado de mudanças tecnológicas provocou consequentes impactos em termos psíquicos, culturais, científicos e inclusive educacionais. Para Santaella (2003, p. 61), a Cibercultura ao instaurar sua "nova ordem econômica, social e cultural mundializada" trouxe consequências para a vida cotidiana, os contextos profissionais e outras possibilidades em termos de lazer e entretenimento. Percebe-se que, por via das experiências, a cultura ciber mantém uma relação indissociável com a formação de si (bildung).

Reconfigurações também ocorreram quanto às formas de registro e síntese da realidade para as utilizações científicas, artísticas e educacionais. Isto repercutiu nas práticas e dispositivos em educação criados para desenvolverem o ser no exercício da vida. Educação que se dá via da formação do ser humano com vistas a sua humanização, onde a educação formal contribui nesse sentido quando disponibiliza os conhecimentos produzidos ao longo da história da humanidade.

Nesses termos, para aceitarem as emergentes formas de aprender e formar-se, os professores precisam sair de uma posição descrita por Martín-Barbero (2014, p. 50, 52) como “obcecados com o poder maléfico", o que ocorre desde os estudos sobre recepção da televisão até às atuais reflexões acerca das tecnologias digitais. A razão é que há "preconceitos daqueles que não ocultam seu arrogante desprezo". Por isso precisam, conforme Santella (2013, p. 250).

[...] dar boas-vindas às mutações que a hipermídia - entendida como novas configurações de hipersintaxes verbais, visuais e sonoras - está trazendo para a linguagem humana e, consequentemente, para os modos como sentimos, agimos, pensamos, conhecemos e aprendemos

Há então que assumir a hipermídia como “dimensão estratégica da cultura” (MARTÍNBARBERO, 2014, p.52), pois a escola interagirá com essa realidade cibercultural. Até porque o estudante já tem se deslocado em suas experiências para uma posição de interação com a Cultura Digital, fato que o expõe diante de

[...] implicações cognitivas, comunicacionais e culturais que a hipermídia [...] traz para os modos de se produzir, transmitir e receber informação, conhecimento, cultura e arte. As estruturas digitais de produção híbrida de textos, imagens, áudios, vídeos e programações estão criando uma lógica nunca antes vivenciada e explorada [...] (SANTAELLA, 2013, p. 357).

A formação de si (bildung) não se limita às fronteiras institucionais, o que demanda percebêla numa dimensão mais ampla, ou seja, como um processo de formação que transcende a sala de 
aula. Para o estudante imerso na realidade cibercultural demanda-se uma educação que considere seu prévio contexto digital e a partir daí fortaleça sua (auto)formação e (trans)formação. É nesse sentido, que as práticas e os dispositivos educacionais se reconfiguram à hipermídia.

O isso que me passa - em termos de experiências de vida articuladas aos processos de (auto)formação e (trans)formação - se mostra na contemporaneidade como indissociável do contexto hipermidiático. Por assim compreender, o posicionamento docente requerido diante das tecnologias digitais implica não apenas reconhecer as experiências desses estudantes com a hipermídia, mas também de migrá-las da margem para o centro do cenário educacional.

As experiências dos estudantes contemporâneos com a Cibercultura acontecem num isso, carregam no me suas representações, intenções, sentimentos e projetos, para então no passar como percurso deixar suas marcas, seus rastros e etc. Estudantes e professores, como indivíduos que por muito tempo tiveram suas fronteiras bem delimitadas em termos de papéis desempenhados no processo educativo, diante da Cibercultura são agora envolvidos numa outra dinâmica.

Uma cultura participativa em que cada "um pode tornar-se produtor, criador, compositor, montador, apresentador, difusor" (SANTAELLA, 2003, p. 82) daquilo que possa inclusive se dá via práticas ou dispositivos educacionais. Uma participação mediada pelas tecnologias digitais e que pode contribuir para uma participação social de estudantes e professores em âmbito sócio educacional.

O pluralismo e a célere expansão das mídias, cada vez mais híbridas, levaram Santaella (2010, p. 16) a aportar-se na metáfora da ecologia a fim de referir-se à "multiplicação nos modos de acessibilidade que a digitalização provoca nas mídias tradicionais, [...] [e às] mídias [...] que brotam diretamente do potencial do computador para criar linguagens que lhe são próprias”.

Isto porque, a fertilidade oriunda dessa expansão fez crescer $a$ semiodiversidade (a diversidade semiótica) das mídias, aumentar as misturas entre elas e se multiplicar as possibilidades de seus usos (SANTAELLA, 2010), efeitos esses capazes de repercutir de forma distinta na vida social. Algumas de suas repercussões educacionais foram abordadas pela autora (SANTAELLA, 2013).

O estudante em processo de formação de si (bildung) ao exercer seu nível de independência de pensamento que lhe permite a reflexão por si e sobre si numa (auto)formação é levado a uma transformação (umbildung). Essa experiência se dá no contato não apenas com o outro, mas com o mundo, o que na Cibercultura se mostra como um mundo imerso numa ecologia pluralista da comunicação (SANTAELLA, 2010). 
Esse indivíduo que em suas experiências (auto)forma-se e se (trans)forma em tempos de uma ecologia das mídias tem sua cognição afetada, e ao

[...] afetar a cognição, produz repercussões cruciais na educação. Novas maneiras de processar a cultura estão intimamente conectadas a novos hábitos mentais que, segundo o pragmatismo, desaguam em novos modos de agir. Os desafios apresentados por essas emergências deveriam colocar sistemas educacionais em estado de prontidão (SANTAELLA, 2013, p. 18).

Sobre a experiência no processo de formação, vimos que Leite (2016) diz que ao se (trans)formar, o indivíduo se afasta de si mesmo e vai ao encontro do mundo, e depois retorna para si. Assim, das experiências com as tecnologias digitais em suas potencialidades faz que o retorno para si ocorra de modo que potencialize a formação de si, isto ocorre a partir das renovações, dos amadurecimentos e das humanizações que lhe sejam proporcionadas.

No entanto, a consideração da experiência formativa de si (bildung) - como constituída do imprevisível, do indizível e do imprescritível, do impossível e do que não pode ser - permite atentar-se ao fato de que no retorno para si pode também tal potencialização não ocorrer. Afinal, as redes também são lugares de risco, o que implica não negligenciar as negatividades ao se propor práticas e dispositivos educacionais que reconfigurem o papel do estudante e do professor na Cibercultura.

Alguns apontamentos estabelece relações com as resistências dos modelos educacionais institucionalizados em aceitar as emergentes formas de se aprender e formar-se diante da ecologia midiática. Por exemplo, Santaella (2013) fala de um sonambulismo tecnológico, enquanto que Martín-Barbero (2014) de uma escola na defensiva.

Nesse sentido, Santaella (2013) defende uma educação que assuma os riscos provenientes das transformações tecnológicas numa posição teórica e crítica, para assim evitar o tal sonambulismo. Enquanto que a escola na defensiva Martín-Barbero (2014, p. 53) concebe-a como reflexo de um "sistema educativo incapaz de pensar a envergadura das mudanças culturais que emergem na relação das crianças e dos jovens com os meios e as tecnologias audiovisuais e informáticas".

Desse enfoque voltado à Cibercultura, ilumina-se a visão de que na educação formal estudantes e professores precisam deslocar-se de modo a ressignificar as práticas e dispositivos educacionais. Um intento que visa a humanização enquanto fortalecimento da formação de si (bildung) em processos de (auto)formação e (trans)formação experienciados com e na hipermídia. 
Enquanto estudantes têm se deslocado para um status de conexão com novos hábitos mentais, que desaguam em novos modos de agir, isto em consequência das mutações que a hipermídia traz para a linguagem humana em formas de sentir, pensar, conhecer e aprender. Por outro lado, professores são desafiados a deixarem a zona de preconceito, obsessão, arrogância, desprezo em relação às tecnologias digitais, para ocuparem um lugar de reconhecimento da dimensão estratégica que a Cibercultura implica desempenhar na educação.

Tratam-se de deslocamentos que buscam relações possíveis entre Cibercultura e Educação, a partir do isso que me passa com os estudantes na e com a hipermídia. Para esse estudo, há uma preocupação especial com a efetivação do processo democrático no Brasil, na medida em que esse fenômeno amplia a importância da educação. As implicações que daí decorrem se intensificam quando se vive num momento histórico em que há uma imersão crescente na Cultura Digital.

As transformações provocadas por ela conduz a uma cultura participativa, em consequência das malhas sociais que se proliferam nas redes e tomam o primeiro plano (SANTAELLA, 2013). As mídias digitais explodiram e estudantes e professores na atualidade "podem ter acesso, arquivar, anotar, apropriar-se, remixar e compartilhar conteúdos multimidiáticos de maneira impensável" (SANTAELLA, 2013, p. 94). Com isso, há oportunidades em termos de aprendizados, de expressão, mas também de engajamento político.

Ao engajar-se politicamente por meio das tecnologias digitais estudantes e professores podem envolver-se com o ativismo nas redes ou ciberativismo (SANTAELLA, 2013). Portanto, temos uma participação social ampliada pelas plataformas de comunicação que se engendram com a evolução hipermidiática. Para Lemos (s/d, p. 2) o ciberativismo "refere-se a práticas sociais associativas de utilização da Internet por movimentos politicamente motivados, com o intuito de alcançar suas novas e tradicionais metas". Além de "mobilizar, informar e agir, tendo como suporte essencial de luta as [tecnologias digitais]" (s/d, p. 2).

Das três categorias explicitadas pelo autor, duas se mostram relevantes a uma educação que se quer atuar na Cibercultura numa perspectiva ativista. Primeiro a de "conscientização e informação", e segundo a de "organização e mobilização, a partir da Internet, para uma determinada ação (convite para ações concretas nas cidades)" (s/d, p. 2). São categorias que direcionam para a atribuição de uma dimensão estratégica das tecnologias digitais na Educação.

Depreende-se com isso que se trata de uma demanda necessária, pois fortalece o deslocamento de uma posição na defensiva para uma educação que se mostra ativista na Cibercultura. Isto, em termos de apropriar-se crítica e criativamente das mídias digitais, numa 
dimensão educacional de humanização e evidentemente não dissociada da formação de si (bildung) dos estudantes.

Os movimentos sociais na cultura contemporânea, não mais dependem estritamente dos espaços físicos (praças públicas, estradas, avenidas, instituições públicas etc.) para alcançar seus objetivos. Eles dispõem dos artefatos tecnológicos e por aproveitá-los estrategicamente, crescem, ganham aceleração e amplitude. Na Cibercultura há

[...] uma pluralidade de grupos com preocupações, interesses e comprometimentos comuns. Esses grupos defendem os direitos humanos das minorias, apoiam, entre outras as causas ambientais, ecologia, desenvolvimento sustentável, reforma agrária, educação, arte e cultura. Suas formas de atuação, sua abrangência - local, regional, nacional ou internacional - e seu limite de tempo - curto, médio e longo prazo - são igualmente plurais (SANTAELLA, 2013, p. 103).

Percebe-se até aqui que no elo defendido entre a Cibercultura, as experiências que delas decorrem e uma educação institucionalizada pode-se fortalecer a formação de si (bildung) no indivíduo que se encontra imerso na dinâmica hipermidiática da cultura contemporânea. Esse fortalecimento se encontra na atualidade com ressignificações em emergência, e com relações diretas com a ampliação da importância da educação diante do processo democrático.

Conclui-se que o elo entre Cibercultura, experiências e educação aponta para a necessidade de conceber novos olhares que se dirijam a uma educação não apenas emancipatória, mas também ativista. Nesse sentido, o engajamento político de estudantes com a hipermídia se mostra como uma das pautas indispensáveis em termos de possibilidades de uma apropriação crítica e criativa das mídias digitais, para assim materializar uma educação ativista na Cibercultura.

\section{CONSIDERAÇÕES FINAIS}

Ao olhar para a educação em sua dimensão mais ampla se reconhece que, enquanto formação humana, ela não se limita a fronteiras institucionais, mas extrapola os espaços físicos educacionais. Diante da Cibercultura isto implica em reconfigurações das práticas e dispositivos educacionais. Portanto, a educação formal como um isso que me passa no exercício da vida do estudante deve também deixar marcas na formação de si (bildung) ao considerar suas experiências ciberculturais.

Esse processo de formação ao encontrar sentido pela via da experiência requer o deslocamento para o centro do processo educativo das emergentes formas de aprender e formar-se 
advindas com as mutações que a hipermídia trouxe para a linguagem humana. Afinal, no retorno para si diante das experiências com a hipermídia deixam-se rastros e marcas nos modos de sentir, agir, pensar, conhecer, aprender tanto de estudantes quanto de professores.

A educação formal deve então assumir as demandas ciberculturais de modo que contribua para uma humanização do estudante, um ser cultural que se (auto)forma e se (trans)forma num cenário onde ele pode produzir, criar, compor, montar, apresentar e difundir aquilo que lhe marca via experiência. Assim, escolas e universidades não devem ficar numa defensiva que reflita incapacidade de pensar as implicações ciberculturais, tampouco num sonambulismo sem se posicionar teórica e criticamente.

Compreende-se ainda que a formação de si (bildung) potencializa a Cibercultura como fenômeno reconfigurante do contexto educacional. Daí espera-se que as experiências prévias dos estudantes migrem da margem dos espaços de educação formal para uma posição central em seu processo educacional, para o isso que me passa em contextos digitais dispor de existência e significância na educação contemporânea.

Por fim, constata-se que a conexão defendida no texto entre Cibercultura, experiências e educação formal se mostra capaz de potencializar uma concepção educacional que busca alternativas inovadoras numa pluralidade que fortaleça a resistência e a luta por uma sociedade mais justa e democrática. Nesse sentido, aproximar-se de uma educação ativista na Cibercultura. 


\section{REFERÊNCIAS}

ARAÚJO, Alberto Filipe; RIBEIRO, José Augusto Lopes. Educação e formação do humano: bildung e romance de formação. In: SEVERINO, Antônio Joaquim; ALMEIDA, Cleide Rita Silvero de; LORIELI, Marcos Antônio (Org.). Perspectiva da Filosofia da Educação. São Paulo: Cortêz, 2017. Cap. 5. p. 120-132.

BRITTO, Fabiano de Lemos. Identidade cultural e formação individual: a Alemanha do século XIX e a fundação da pedagogia moderna. Educação e Sociedade,vol.33, n.118, pp, 217-233. 2012. Disponível em: http://www.scielo.br/ scielo.php?pid=S0101-73302012000100014\&script=sci_abstract\&tlng=pt. Acesso em: 22 mai. De 2019.

GOERGEN, P. O embate modernidade/pós-modernidade e seu impacto sobre a teoria e a prática educacionais. Eccos Revista Científica, 28, 149-169. 2012. Disponível em: https://www.redalyc.org/pdf/715/71523339010.pdf. Acesso em: 23 de jan. 2019.

TOMMASELLI, G. C. G. Formação (bildung), cuidado de si, vivências e educação. Revista Aufklärung, João Pessoa, v.4, n.1, Jan.Abr.,p.91102. 2017. Disponível em: http://www.periodicos.ufpb.br/ojs/index.php/arf/article/view/30658. Acesso em: 23 de jan. 2019.

JOHNSON, Allan. Dicionário de sociologia: guia prático da linguagem sociológica. Rio de Janeiro: Jorge Zahar Editor, 1997.

LARROSA, Jorge. Experiência e alteridade em educação. Revista Reflexão e Ação, Santa Cruz do Sul, v.19, n2, p.0427, jul./dez. 2011.

LEITE, Rita de Cássia Nascimento. A formação de si (Bildung) do estudante universitário. 2016.195 f. Tese (Doutorado) - Curso de Psicologia, Faculdade de Filosofia e Ciências Humana, Universidade Federal da Bahia, Salvador, 2016. Disponível em: https://repositorio.ufba.br/ri/handle/ri/24063. Acesso em: 22 maio 2019.

LEMOS, André. Ciberativismo. Disponível em https://www.facom.ufba.br/ciberpesquisa/lemos/ciberativismo.pdf. Acesso em 05 jun. 2019.

MARTIN-BARBERO, Jesús. A comunicação na educação. Tradução: Maria Immacolata Vassallo de Lopes e Dafne Melo. São Paulo: Contexto, 2014.

SANTAELLA, Lúcia. Culturas e artes do pós-humano: da cultura das mídias à cibercultura. São Paulo: Paulus, 2003.

Comunicação ubíqua: repercussões na cultura e na educação. São Paulo: Paulus, 2013.

Ecologia Pluralista da Comunicação: conectividade, mobilidade e ubiquidade. São Paulo: Paulus, 2010.

SEVERINO, Antônio Joaquim. A busca do sentido da formação humana: tarefa da filosofia da educação. Educação e Pesquisa, v.32, n. 3, pp. 619-634. 2006

VIEIRA, Carlos Eduardo. Cultura e Formação Humana no Pensamento de Antonio Gramsci. Educação e Pesquisa, São Paulo, v. 25, n. 1, p. 51-66, jan./jun. 1999.

XAVIER, Antônio Carlos. Reflexões em torno da escrita nos novos gêneros digitais da Internet. Revista Investigações

- Linguística e Teoria Literária, João Pessoa, v. 4, n. 18, p.60-75, ago. 2005. Semestral. Disponível em: https://periodicos.ufpe.br/revistas/INV/issue/view/84/showToc. Acesso em: 15 set. 2018. 


\section{RESUMO}

O estudo aborda o processo de formação humana e suas múltiplas relações com a educação institucionalizada e a cultura contemporânea (Cibercultura). Assume a formação de si (bildung) como princípio diretivo no curso da vida e como impulsionadora de práticas de vivência e convivência em meio as diversidades que marcam a contemporaneidade. Ao tempo em que aponta a cultura ciber como propulsora de reconfiguração do contexto educativo e do papel dos seus atores, docentes e discentes. O texto se constitui como uma revisão bibliográfica de base teórica. Constata-se que a Cibercultura reconfigura o contexto educativo por abrir espaço à experiências prévias dos estudantes, à cultura e à relações sociais mais horizontalizadas.

Palavras-chaves: Bildung. Cibercultura. Educação.

\section{THE FORMATION OF SI (BILDUNG) IN EDUCATIONAL CONTEXT CONFIGURED BY CYBERCULTURE}

\section{ABSTRACT}

The study addresses the process of human formation and the relationships with institutionalized education in contemporary culture (Cyberculture). It assumes the formation of self (bildung) is prime of life end it promotes practices of living and coexistence in contemporaneity. At the same time, cyber culture configure the educational context and the role of actors, teachers and students. The text is a bibliographical revision. As a result, it is verified that the Cyberculture configures in educational context by opening space to previous experiences of the students, to the culture and to the more horizontalized social relationships.

Keywords: Bildung. Cyberculture. Education.

\section{LA FORMACIÓN DE SI (BILDUNG) EN CONTEXTO EDUCATIVO CONFIGURADO POR LA CIBERCULTURA}

\section{RESUMEN}

El estudio aborda el proceso de formación humana y las múltiples relaciones con la educación institucionalizada e la cultura contemporánea (Cibercultura). Asume la formación de sí (bildung) como principio directivo el curso de la vida y como impulsora de prácticas de vivencia y convivencia en medio de las diversidades que marcan la contemporaneidad. Al tiempo en que apunta la cultura ciber como propulsora de reconfiguración del contexto educativo y del papel de sus actores, docentes y discentes. El texto se constituye como una revisión bibliográfica de base teórica. Se constata que la Cibercultura reconfigura el contexto educativo por abrir espacio a las experiencias previas de los estudiantes, a la cultura ya las relaciones sociales más horizontalizadas.

Palabras claves: Bildung. Cibercultura. Educación.

Submetido em Julho de 2019 Aprovado em Movembro de 2019 